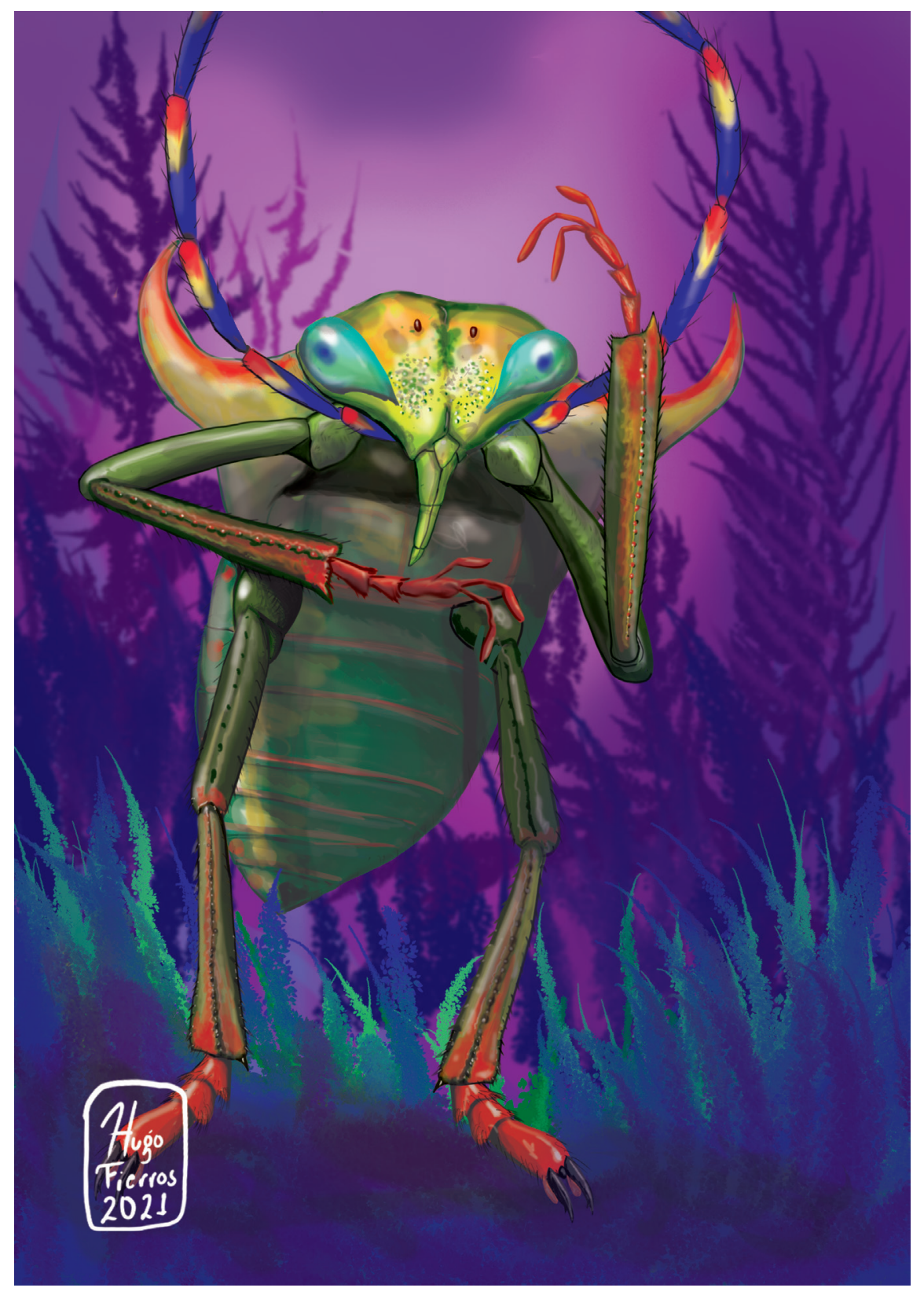

Dugesiana, Año 29, No. 1, (enero-junio, primer semestre 2022), es una publicación semestral, editada por la Universidad de Guadalajara, a través del Centro de Estudios en Zoología, por el Centro Universitario de Ciencias Biológicas y Agropecuarias. Camino Ramón Padilla Sánchez \# 2100, Nextipac, Zapopan, Jalisco, Tel. 37771150 ext. 33218, http://148.202.248.171/dugesiana/index.php/DUG/index, glenusmx@gmail.com. Editor responsable: José Luis Navarrete-Heredia. Reserva de Derechos al Uso Exclusivo 04-2009-062310115100-203, ISSN: 20079133, otorgados por el Instituto Nacional del Derecho de Autor. Responsable de la última actualización de este número: José Luis Navarrete-Heredia, Editor y Ana Laura González-Hernández, Asistente Editorial. Fecha de la última modificación 1 de enero de 2022, con un tiraje de un ejemplar.

Las opiniones expresadas por los autores no necesariamente reflejan la postura del editor de la publicación.

Queda estrictamente prohibida la reproducción total o parcial de los contenidos e imágenes de la publicación sin previa autorización de la Universidad de Guadalajara. 


\title{
Dr. Jorge Llorente-Bousquets: lepidópterologo mexicano reconocido con la Karl Jordan Medal
}

\author{
Dr. Jorge Llorente-Bousquets: Mexican lepidopterologist recognized with The Karl Jordan Medal
}

\section{Liliana P. Sandoval}

Centro de Estudios en Zoología, Centro Universitario de Ciencias Biológicas y Agropecuarias, Universidad de Guadalajara. Camino Ramón Padilla Sánchez 2100 Nextipac, 45200 Zapopan, Jalisco

La Sociedad de Lepidopterólogos (The Lepidopterists' Society) otorga un reconocimiento a un investigador destacado por su investigación sobresaliente en el ámbito de la lepidopterología. Dicha distinción es conocida como The Karl Jordan Medal.. Para ser acreedor de tal reconocimiento tiene que haber unanimidad por parte del comité de selección, por esta razón la medalla no se entrega cada año, asegurando que el premio se otorgue a una persona que realice investigación de alta calidad.

Este año, dicho premio fue otorgado al Dr. Jorge Llorente-Bousquets, quien dio una ponencia para expresar su gratitud con la Sociedad. En esta conferencia, el Dr. Llorente se dijo estar muy sorprendido y halagado por ser considerado como uno de los lepidopterólogos más importantes del último medio siglo.

Esto sin duda es motivo de celebración para la comunidad entomológica de México, pues es un reconocimiento en el que el comité de la Sociedad de Lepidopterólogos busca a la persona idónea, quien además de hacer investigación de alta calidad, fomente los valores que Karl Jordan difundió durante toda su vida como entomólogo, los cuales son la cooperación, el mantener una buena relación con los compañeros de trabajo y la excelencia.

Cuando hablamos del Dr. Llorente es fácil pensar en todas sus aportaciones a la sistemática, biogeografía, taxonomía y entomología de México, sin embargo, personalmente, hablar de él es pensar en sus más de 40 años de investigación sobre lepidópteros.

Su pasión por las mariposas inició a muy temprana edad, justo en su infancia e incluso su abuela lo llegó a llamar "El maestro de las mariposas". Durante la etapa de universidad conoció a quien sería el profesor más importante que tuvo, Alfredo Barrera, quien, al igual que Karl Jordan, era sifonapterólogo, sin embargo, también estaba interesado en las mariposas, la taxonomía, biogeografía y la etnociencia, esto sin duda propició que el interés del Dr. Llorente por los lepidópteros aumentara.

Al echar un vistazo a su trayectoria profesional podemos darnos cuenta de sus 48 años trabajando en la Universidad Nacional Autónoma de México. Pero no es solamente en la UNAM donde ha realizado investigación, pues también ha visitado otras instituciones como el Museo Nacional de Historia Natural Smithsoniano, el Museo de Entomología de Allyn, el Centro McGuire de la Universidad de Florida, el Instituto de Ciencias Naturales UNAL Bogotá, el Museo Americano de Historia Natural y el Museo Británico de Historia Natural.

Durante estas visitas él tuvo la fortuna de conocer y entablar amistad con varios de sus colegas esto también le dio la oportunidad de realizar trabajo de campo en varios países: México, Estados Unidos, Colombia, Ecuador, Guatemala, Inglaterra y Austria, por mencionar algunos.

El Dr. Llorente ha sido acreedor a varios cargos por su trabajo en la biología, dentro de los más importantes están ser el primer director del Museo de Zoología de la Facultad de Ciencias, UNAM, director de Análisis y Prioridades de CONABIO y coordinador de la Red iberoamericana de Biogeografía y Entomología por CYTED-RIBES. Entre los reconocimientos que se le han dado se encuentra el ser nombrado profesor emérito por la UNAM e Investigador Nacional Emérito por CONACYT, y en el 2019 fue homenajeado por la Universidad de Guadalajara y se le dedicó un volumen de la revista Dugesiana.

A lo largo de su carrera ha publicado 450 productos, entre los que se encuentran 182 artículos, 67 libros, 152 capítulos de libros y 10 publicaciones electrónicas, siendo el $48 \%$ de estas centradas en lepidópteros.

Dentro de sus grupos de estudio, la familia Pieridae es su favorita y la ha usado como modelo biológico para sus estudios y a la subfamilia Dismorphiinae como modelos para estudiar el mimetismo batesiano en el Neotrópico.

Una de sus más grandes contribuciones al estudio de Lepidoptera es la colección de libros titulados Mexican Butterflies, de la cual el primer libro trató sobre las familias Papilionidae y Pieridae, mientras que los tres libros subsecuentes han sido sobre las subfamilias de Nymphalidae y otros tres volúmenes se tienen en preparación.

Actualmente se cuenta con una base de datos de Lepidoptera del Museo de Zoología, Facultad de Ciencias, UNAM, que rebasa los 530,000 registros, todos estos con datos georreferenciados, convirtiéndola en la base más grande de México y de América Latina de mariposas. El Dr. Llorente menciona que esto no habría sido posible de no ser por el esfuerzo de sus dos colegas y amigos Armando Luis e Isabel Vargas, a los cuales les cedió la batuta de la base que él inició entre 1984 y 1985. 
Entre sus trabajos más recientes e importantes se encuentran los que han sido centrados en algunos géneros de Dismorphiinae y en el estudio de la morfología y las microestructuras, en particular de las antenas de Pieridae y el corion de Pieridae, Nymphalidae y Riodinidae.
Por esta razón se hace una extensa felicitación al Dr. Jorge Llorente-Bousquets por tan merecido premio.

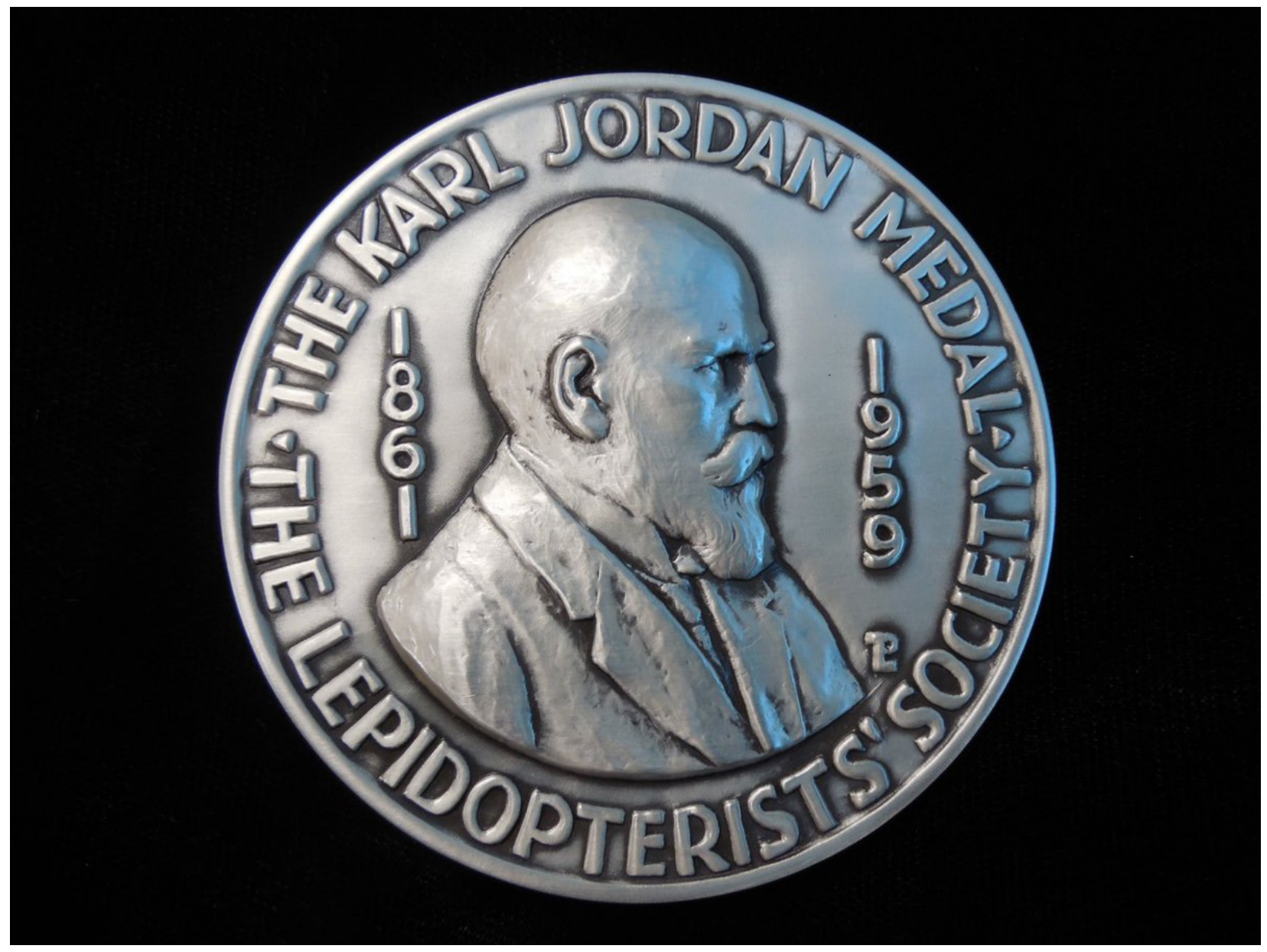

Recibido: 17 de diciembre 2021

Aceptado: 17 de diciembre 2021 